\title{
Use of sourdough lactobacilli and oat fibre to decrease the glycaemic index of white wheat bread
}

\author{
Maria De Angelis ${ }^{1}$, Carlo G. Rizzello ${ }^{1}$, Giuditta Alfonsi ${ }^{1}$, Philip Arnault $^{2}$, Stefan Cappelle ${ }^{2}$, \\ Raffaella Di Cagno ${ }^{1}$ and Marco Gobbetti ${ }^{1}$ * \\ ${ }^{1}$ Dipartimento di Protezione delle Piante e Microbiologia Applicata, Università degli Studi di Bari, Via G. Amendola 165/a, \\ 70126 Bari, Italy \\ ${ }^{2}$ Puratos N.V., Industrialaan 25 B-1702, Groot-Bijgaarden, Belgium
}

(Received 27 November 2006 - Revised 20 April 2007 - Accepted 30 April 2007)

This work was aimed at decreasing the glycaemic index (GI) of white wheat bread. Breads made with wheat flour (WF) or wholemeal flour (WMF) and fermented with baker's yeast had similar values of resistant starch (RS; 1.4-1.7\%, starch basis). Sourdough Lactobacillus plantarum P1 and Lactobacillus brevis $\mathrm{P} 2$ favoured the highest formation of RS (approximately $5 \%$ ) when fermented with WF and WMF. The mixture (1:1) of WF and WMF (WF/WMF) was selected. The effect of dietary fibres, chemical or sourdough acidification on the hydrolysis index (HI) of WF/WMF bread was determined. Among fibres, only the addition of oat fibre (5\%) decreased the HI to $90.84 \%$. Lactic acid determined the lowest HI, and the effect was related to the decrease of $\mathrm{pH}$. For the same decrease of $\mathrm{pH}$, breads fermented with L. plantarum $\mathrm{P} 1$ and L. brevis $\mathrm{P} 2$ (sourdough WF/ WMF) showed values of HI lower than chemical acidification. The glucose response and GI of WF bread or sourdough WF/WMF bread enriched with oat fibre was determined by using fifteen healthy volunteers. Anhydrous glucose was used as reference. The area under the glucose response curve and the value of GI $(72 \%)$ of WF bread were significantly $(P<0.05)$ higher than sourdough WF/WMF bread enriched with oat fibre $(\mathrm{GI}=53.7 \%)$. The decrease of GI of the sourdough WF/WMF bread may be due to both fibre content and decreased pH. Compared to WMF bread, sourdough WF/WMF bread, enriched with oat fibre, had higher specific volume, better cell crumb structure and more appreciated acidulous smell, taste and aroma.

Glycaemic index: White wheat bread: Lactobacilli: Oat fibre

The glycaemic index (GI) is the measure of the power of food to raise the concentration of B-glucose in the blood after a meal. GI is defined as the ratio between the incremental area under the B-glucose response curve of the tested meal containing $50 \mathrm{~g}$ digestible carbohydrates and the incremental area under the B-glucose response curve of the standard food, i.e. $50 \mathrm{~g}$ pure glucose. Overall, carbohydrates that break down quickly during digestion have a high GI since their B-glucose response is fast and high. Carbohydrates that break down slowly have a low $\mathrm{GI}^{1}$.

Several large-scale, observational studies from Harvard University (Cambridge, MA, USA) indicate that long-term consumption of a diet with high glycaemic load (GI $\times$ dietary carbohydrate content) is a significant independent predictor of the risk of developing type 2 diabetes ${ }^{2,3}$ and $\mathrm{CVD}^{4}$. More recently, evidence has been accumulating that a low-GI diet might protect against development of obesity ${ }^{5}$, colon cancer and breast cancer ${ }^{6}$. The mechanisms of protection of the low-GI diet may derive from: (1) the slow release of carbohydrates in the upper gastrointestinal tract; (2) the lowering of the insulin demand ${ }^{7}$; and (3) the generally high concentration of indigestible carbohydrates such as dietary fibre and resistance starch (RS), which, in turn, increase the fermentative activity at the colon level. This latter fermentative activity increases the synthesis of propionic acid which is considered the moderator of hepatic glucose ${ }^{8}$ and lipid metabolism ${ }^{9}$. Therefore, the low-GI diet has emerged as an interesting tool in decreasing diseases related to the metabolic syndrome and cereal fibres have been shown to possess a preventive effect (for reviews see Jenkins et al. ${ }^{10}$ and Björck \& Liljeberg $\left.^{11}\right)$.

Based on experimental and epidemiological evidence, the development of low-GI cereal products seems to be particularly relevant from a metabolic perspective ${ }^{11}$. Bread biotechnology as well some bread components may have an influence on glycaemia. Bread leavening by sourdough or the direct addition of acetic, propionic and lactic acids during bread making decreased the postprandial blood glucose and insulin responses (for review see Björck \& Liljeberg ${ }^{11}$ ). Cereal grains are mainly composed of starch and NSP such as $\beta$-glucan, polyfructan and arabinoxylan. Some of these polysaccharides are partially digestible, e.g. starch, while

Abbreviations: GI, glycaemic index; HI, hydrolysis index; RS, resistant starch; WF, wheat flour; WF/WMF, WF and WMF in the ratio of 1:1; WMF, wholemeal flour; $\Delta \mathrm{pH}$, decrease of the initial $\mathrm{pH}$ of the dough.

* Corresponding author: Prof Marco Gobbetti, fax +39080 5442911, email gobbetti@agr.uniba.it 
others are believed to serve as dietary fibres, e.g. arabinoxy$\operatorname{lan}^{12}$. These dietary fibres exert beneficial effects on the reduction of the level of cholesterol and on decreasing the risk of colon cancer (for review see Jenkins et al. ${ }^{13}$ ). Nevertheless, white bread, the most commonly consumed, is manufactured from wheat flours which have a very low concentration of these dietary fibres. Currently, the biotechnology of white bread is considering the manufacture of baked goods enriched with dietary fibres. When fibres or wholemeal are included in the formulas of baked goods, the protocol of manufacture needs the set up of several technological parameters in order to get high-quality and consumer-acceptable breads $^{11,14}$.

The present work was aimed at decreasing the GI of white wheat flour (WF) bread by using selected sourdough lactobacilli and dietary fibres. The GI of selected bread was determined in vivo for fifteen healthy volunteers, and the structural and sensory properties of the resulting bread were characterized.

\section{Materials and methods}

\section{Strains and culture conditions}

Lactobacillus sanfranciscensis DA110, L. plantarum DC400 and $\mathrm{P} 1$, and L. brevis $\mathrm{P} 2$, belonging to the Culture Collection of the Dipartimento di Protezione delle Piante e Microbiologia Applicata, Università degli Studi di Bari, Italy, were used in the present study. Strains were selected previously based on the acidification capacity. Strains were routinely propagated for $24 \mathrm{~h}$ at $30^{\circ} \mathrm{C}$ in modified MRS broth (Oxoid, Basingstoke, UK) with the addition of fresh yeast extract $(5 \% \mathrm{v} / \mathrm{v})$ and $28 \mathrm{~mm}$-maltose at final $\mathrm{pH} 5 \cdot 6$.

\section{Wheat flour breads fermented with sourdough lactobacilli:} preliminary screening

The white WF (Triticum aestivum, var. S. Pastore) used had the characteristics reported in Table 1. L. sanfranciscensis DA110, L. plantarum DC400, L. plantarum $\mathrm{P} 1$ and L. brevis P2 were used for dough fermentation to select the most appropriate starter based on the formation of resistant starch (RS). Cells of each strain ( $24 \mathrm{~h}$ old) cultivated in modified MRS were harvested by centrifugation $\left(9000 \mathrm{~g}, 10 \mathrm{~min}, 4^{\circ} \mathrm{C}\right)$, washed twice with $50 \mathrm{~mm}$-sterile potassium phosphate buffer $(\mathrm{pH} 7 \cdot 0)$ and resuspended in sterile distilled water to a final optical density at $620 \mathrm{~nm}$ of $2.5\left(10^{9}\right.$ colony-forming units/ $\mathrm{ml})$. WF $(312 \mathrm{~g}), 133 \mathrm{~g}$ sterilized distilled water and $50 \mathrm{~g}$ of the cellular suspension, containing $10^{9}$ colony-forming units/ $\mathrm{ml}$ of DA110, DC400, P1 or P2 strains (final cell number of approximately $5 \times 10^{8}$ colony-forming units/g dough), and
$5 \mathrm{~g}$ baker's yeast were used to produce $500 \mathrm{~g}$ dough (dough yield, dough weight $\times 100 /$ flour weight, 160) with a continuous high-speed mixer (60g; dough mixing time, 5 min; Chopin \& Co., Boulogne, France). A control dough without bacterial inoculum was prepared also. All the doughs were fermented at $30^{\circ} \mathrm{C}$ for $3 \mathrm{~h}$ and baked at $220^{\circ} \mathrm{C}$ for $50 \mathrm{~min}$. All experiments were carried out using wholemeal flour (WMF) also (Table 1).

\section{Bread making with dietary fibres, chemical acidification or sourdough}

Three different dietary fibres (dextran, sugarbeet and oat fibres) were kindly supplied by Puratos n.v. (Groot-Bijgaarden, Belgium). The chemical composition of the dietary fibres is shown in Table 1. The following flours and fibres were used: (1) WF; (2) WMF; (3) WF and WMF in the ratio of 1:1 (WF/WMF); (4) WF/WMF and dextran; (5) WF/ $\mathrm{WMF}$ and sugarbeet fibre; and (6) WF/WMF and oat fibre (Table 2).

To study the influence of chemical acidification, the following ingredients were used: (1) WF/WMF; (2) WF/WMF acidified with acetic acid to decrease the initial $\mathrm{pH}$ of the dough by 0.5 unit $(\Delta \mathrm{pH} 0.5)$; (3) WF/WMF acidified with a mixture of lactic and acetic acids (ratio of $1: 4$ ) to $\Delta \mathrm{pH} 0.5$; and (4) WF/WMF acidified with lactic acid to $\Delta \mathrm{pH} 0.5,1.0$ or 1.5 (Table 2).

L. plantarum $\mathrm{P} 1$ and L. brevis $\mathrm{P} 2$ were selected and used as sourdough to ferment dietary fibre-enriched breads. The initial cell density in the dough varied according to the $\Delta \mathrm{pH}$ to be reached after $3 \mathrm{~h}$ of fermentation at $30^{\circ} \mathrm{C}\left(1 \times 10^{7}, 5 \times 10^{7}\right.$ or $5 \times 10^{8}$ colony-forming units/g for $\Delta \mathrm{pH} 0.5,1.0$ or 1.5 , respectively). All WF, WMF and WF/WMF were fermented by sourdough to $\Delta \mathrm{pH} 0.5,1.0$ or 1.5 . Sourdough WF/WMF, containing dextran, sugarbeet fibre or oat fibre, was also fermented to $\Delta \mathrm{pH} 0.5-1.5$ (Table 2).

All the doughs were fermented at $30^{\circ} \mathrm{C}$ for $3 \mathrm{~h}$ and baked at $220^{\circ} \mathrm{C}$ for $50 \mathrm{~min}$. For each condition, three independent experiments were carried out.

\section{Determination of $\mathrm{pH}$ and physico-chemical analyses}

The values of $\mathrm{pH}$ were determined by a Foodtrode electrode (Hamilton, Bonaduz, Switzerland). Moisture was determined according to the standard American Association of Cereal Chemists method ${ }^{15}$. Nitrogen content was measured by the semimicro-Kjeldahl method. Protein was calculated by multiplying the nitrogen concentration $\times 5 \cdot 7$. Carbohydrates were determined by HPLC ${ }^{14}$. Soluble, insoluble and total dietary

Table 1. Chemical composition of wheat flours and dietary fibres used in the present study

\begin{tabular}{|c|c|c|c|c|c|c|}
\hline \multirow[b]{2}{*}{ Product } & \multicolumn{6}{|c|}{ Composition (\%) } \\
\hline & Water & Proteins & Lipids & Carbohydrates & Insoluble fibre & Soluble fibre \\
\hline Wheat flour (Triticum aestivum) & $14 \cdot 2$ & $11 \cdot 5$ & $1 \cdot 0$ & $72 \cdot 4$ & $1 \cdot 8$ & $1 \cdot 1$ \\
\hline Wholemeal wheat flour (Triticum aestivum) & $13 \cdot 4$ & 11.9 & 1.9 & $70 \cdot 2$ & $6 \cdot 5$ & 1.9 \\
\hline Dextran & $14 \cdot 0$ & $11 \cdot 0$ & 0.5 & $80 \cdot 0$ & $20 \cdot 0$ & $60 \cdot 0$ \\
\hline Oat fibre & $10 \cdot 0$ & 0 & 0 & $89 \cdot 0$ & $40 \cdot 0$ & $49 \cdot 0$ \\
\hline Sugarbeet fibre & $10 \cdot 0$ & $10 \cdot 0$ & 0.3 & $76 \cdot 5$ & $22 \cdot 0$ & $51 \cdot 0$ \\
\hline
\end{tabular}


Table 2. Ingredients used for bread making*

\begin{tabular}{|c|c|c|c|c|c|c|c|c|}
\hline Breads & $\begin{array}{l}\text { WF } \\
(\mathrm{g})\end{array}$ & $\begin{array}{l}\text { WMF } \\
\text { (g) }\end{array}$ & $\begin{array}{l}\text { Water } \\
\text { (g) }\end{array}$ & $\begin{array}{l}\text { Dextran } \\
\text { (g) }\end{array}$ & $\begin{array}{l}\text { Sugarbeet fibre } \\
\text { (g) }\end{array}$ & $\begin{array}{l}\text { Oat fibre } \\
\text { (g) }\end{array}$ & $\begin{array}{l}\text { Lactic acid } \\
(\mathrm{mmol} / \mathrm{l})\end{array}$ & $\begin{array}{c}\text { Acid acetic } \\
(\mathrm{mmol} / \mathrm{l})\end{array}$ \\
\hline WF & $312 \cdot 0$ & & $188 \cdot 0$ & & & & & \\
\hline \multicolumn{9}{|l|}{ Fibre-enriched breads } \\
\hline WMF & & $312 \cdot 0$ & $188 \cdot 0$ & & & & & \\
\hline WF/WMF & $156 \cdot 0$ & $156 \cdot 0$ & $188 \cdot 0$ & & & & & \\
\hline WF/WMF and dextran & 143.5 & 143.5 & $188 \cdot 0$ & $25 \cdot 0$ & & & & \\
\hline WF/WMF and sugarbeet fibre & 143.5 & 143.5 & $188 \cdot 0$ & & $25 \cdot 0$ & & & \\
\hline WF/WMF and oat fibre & 143.5 & 143.5 & $188 \cdot 0$ & & & $25 \cdot 0$ & & \\
\hline \multicolumn{9}{|l|}{ Chemically acidified breads } \\
\hline WF/WMF and acetic acid ( $\Delta \mathrm{pH} 0.5)$ & $156 \cdot 0$ & $156 \cdot 0$ & $188 \cdot 0$ & & & & & 3.88 \\
\hline WF/WMF and lactic acid ( $\Delta \mathrm{pH} 0.5)$ & $156 \cdot 0$ & $156 \cdot 0$ & $188 \cdot 0$ & & & & $2 \cdot 24$ & \\
\hline WF/WMF and lactic and acetic acid ( $\Delta \mathrm{pH} 0.5)$ & $156 \cdot 0$ & $156 \cdot 0$ & $188 \cdot 0$ & & & & 1.95 & 0.48 \\
\hline WF/WMF and lactic acid $(\Delta \mathrm{pH} 1.0)$ & $156 \cdot 0$ & $156 \cdot 0$ & $188 \cdot 0$ & & & & 4.60 & \\
\hline WF/WMF and lactic acid ( $\Delta \mathrm{pH} 1.5)$ & $156 \cdot 0$ & $156 \cdot 0$ & $188 \cdot 0$ & & & & $6 \cdot 60$ & \\
\hline \multicolumn{9}{|l|}{ Breads fermented by sourdough lactobacilli } \\
\hline WF/WMF $(\Delta \mathrm{pH} 0.5 ; 1.0 ; 1.5)$ & $156 \cdot 0$ & $156 \cdot 0$ & $188 \cdot 0$ & & & & & \\
\hline WF/WMF and dextran $(\Delta \mathrm{pH} 0.5 ; 1.5)$ & 143.5 & 143.5 & $188 \cdot 0$ & $25 \cdot 0$ & & & & \\
\hline WF/WMF and sugarbeet fibre $(\Delta \mathrm{pH} 0.5 ; 1.5)$ & 143.5 & 143.5 & $188 \cdot 0$ & & $25 \cdot 0$ & & & \\
\hline WF/WMF and oat fibre $(\Delta \mathrm{pH} 0.5 ; 1.5)$ & 143.5 & 143.5 & $188 \cdot 0$ & & & $25 \cdot 0$ & & \\
\hline
\end{tabular}

$\mathrm{WF}$, white wheat flour bread; WF/WMF, WF and WMF in the ratio of $1: 1$; WMF, wholemeal flour bread; $\Delta \mathrm{pH}$, decrease of the initial $\mathrm{pH}$ of the dough.

${ }^{*}$ All dough contained $1.0 \%$ of baker's yeast. For details about bread making, see Materials and Methods.

fibres were determined according to the American Association of Cereal Chemists method ${ }^{16}$.

Total starch was analysed as described by Holm et al. ${ }^{17}$. Factor conversion from glucose to starch was 0.9. The RS and potentially available starch was determined using the in vitro method described by Åkerberg et al. ${ }^{18}$. Factor conversion from glucose to starch was 0.9 .

\section{In vitro starch hydrolysis}

The analysis of starch hydrolysis simulates the in vivo digestion of $\operatorname{starch}^{19}$. All bread portions contained $1 \mathrm{~g}$ starch and were given in randomized order to ten volunteers. Subjects rinsed their mouths with tap water and subsequently chewed the bread products for $15 \mathrm{~s}$ (approximately fifteen times). They were told not to eat within $1 \mathrm{~h}$ prior to the experiment. The products were then expectorated into a beaker containing $50 \mathrm{mg}$ pepsin in $6 \mathrm{ml}$ of $0.05 \mathrm{M}-\mathrm{Na}, \mathrm{K}$-phosphate buffer (containing $0.4 \mathrm{~g} / \mathrm{l} \mathrm{NaCl}$ ) adjusted to $\mathrm{pH} 1.5$ with $2 \mathrm{M}-\mathrm{HCl}$. Finally, the subjects rinsed their mouths with $5 \mathrm{ml} 0.05 \mathrm{M}-\mathrm{Na}, \mathrm{K}$-phosphate buffer ( $\mathrm{pH} \mathrm{6.9)}$ for $60 \mathrm{~s}$ and expectorated the rinsing solution into the beaker. The contents were stirred and $\mathrm{pH}$ adjusted to 1.5. Each sample was incubated at $37^{\circ} \mathrm{C}$ for $30 \mathrm{~min}$ with gentle mixing three times during incubation. The $\mathrm{pH}$ was readjusted to 6.9 with $\mathrm{NaOH}$ before incubation with porcine pancreatin $\alpha$-amylase (110 U; Sigma, St Louis, MO, USA). The enzyme was dissolved in $10 \mathrm{ml}$ buffer, and $1 \mathrm{ml}$ of this solution was added to the beaker. The sample was brought to volume $(30 \mathrm{ml})$ with $0.05 \mathrm{M}-\mathrm{Na}, \mathrm{K}$-phosphate buffer, and transferred to the dialysis tubing (cut-off 12400 ). Each bag was incubated at $37^{\circ} \mathrm{C}$ for $3 \mathrm{~h}$ in a beaker with $0.05 \mathrm{M}-\mathrm{Na}, \mathrm{K}$-phosphate buffer $(800 \mathrm{ml})$. The beaker was placed in a stirred water-bath. Every $30 \mathrm{~min}$, aliquots $(2 \mathrm{ml})$ from the dialysate were removed and refrigerated. Then $3 \mathrm{ml} \mathrm{0.4} \mathrm{M-sodium} \mathrm{acetate} \mathrm{buffer} \mathrm{(} \mathrm{pH} 4.75)$ were added to each aliquot, and $80 \mu \mathrm{l}$ amyloglucosidase $(140 \mathrm{U} / \mathrm{ml})$ were used to hydrolyse the digested starch into glucose after $45 \mathrm{~min}$ at $60^{\circ} \mathrm{C}$ in a shaking water-bath. The glucose content was measured with Enzy Plus D-Glucose (Diffchamb, Italia srl, RM, Italy). The factor conversion from glucose to starch was 0.9 . The rate of starch digestion was expressed as the percentage of potentially available starch hydrolysed at different times $(30,60,90,120$ and $180 \mathrm{~min})$. The hydrolysis curves were obtained with the following equation, using the program Statistica 6.0 (Statsoft Inc., Tulsa, OK, USA). Hydrolysis curves follow a first-order equation: $C=C_{\infty}\left(1-\mathrm{e}^{-k t}\right)$, where $C$ is the concentration at $t$ time, $C_{\infty}$ is the equilibrium concentration, $k$ is the kinetic constant and $t$ is the chosen time.

\section{Glycaemic index in vivo test}

Fifteen healthy non-smoking volunteers, eight women and seven men, aged 23-55 years, with normal BMI $(21.5 \mathrm{~kg} /$ $\mathrm{m}^{2}$ ) and without drug therapy participated in the present study. Anhydrous glucose and two breads were used for the in vivo test: WF (control) and WF/WMF enriched with oat fibre (Table 2). Available carbohydrates of each bread and anhydrous glucose $(50 \mathrm{~g})$ were consumed in a random order on separate mornings after $10-12 \mathrm{~h}$ overnight fast. The analysis was carried out in triplicate: each volunteer consumed the same sample during a period of $3 \mathrm{~d}$. Samples were consumed over $6 \mathrm{~min}$ with tap water. After anhydrous glucose or bread ingestion, capillary finger-prick blood samples (three or four drops) were taken from volunteers fasting ( 0 min) and after 15, 30, 45, 60, 75, 90, 105 and $120 \mathrm{~min}$. Blood samples were collected into tubes and frozen at $-20^{\circ} \mathrm{C}$ before analysis by the glucose oxidase (EC 1.1.3.4) method $^{20}$.

The areas under the glucose-response curves for each sample were calculated geometrically, excluding beneath the fasting level. GI was calculated by expressing the glycaemic response area for the WF bread and sourdough WF/WMF bread enriched with oat fibre as the percentage of the mean response area of the $50 \mathrm{~g}$ anhydrous glucose ingested by the same volunteers. 
The resulting individual GI values were averaged to obtain the GI value for WF bread and sourdough WF/WMF bread.

\section{Bread characteristics}

The determinations of bread mass and specific volume were carried out according to the American Association of Cereal Chemists 10-10 official method (AACC, 2000, St Paul, MN, USA).

The bread crumb grain was evaluated by using image analysis technology. Images of the sliced breads were captured using an Image Scanner (Amersham Pharmacia Biotech, Uppsala, Sweden). Images were scanned full scale at 300 dots per inch and analysed in grey scale (0-255). Image analysis was performed using the UTHSCSA ImageTool program (version 2.0; University of Texas Health Science Centre, San Antonio, Texas, available by anonymous FTP from maxrad6.uthscsa.edu). A threshold method was used for differentiating gas cells and non-cells. The threshold was determined according to the method of Crowley et al. ${ }^{21}$. Analysis was carried out on two sub-images of $500 \times 500$ pixels selected from within the bread slice. Two slices were analysed per treatment. Gas cell to total area ratio was recovered.

The laboratory acceptance panel was used to give an indication of consumer acceptance of the products under study $^{22}$. Breads, baked the day before sensory testing, were served at room temperature and under normal (daylight) illumination. A serving of each bread, identified by code numbers, on a single tray was served to each panelist. Ten volunteers from laboratory staff evaluated each product for quality attributes: colour, flavour/aroma, elasticity, sweetness and dryness. Acceptability of each quality attribute was rated with a score from 0 (lowest) to 100 (highest) $^{23}$.

\section{Statistical analysis}

Experimental data were subjected to ANOVA and pair-comparison of treatment means was achieved using Tukey's procedure at $P<0.05$ using the statistical software Statistica Windows version 6.0). For the GI in vivo test, the analyses were carried out in triplicate and the capillary finger-prick blood samples (three or four drops) were taken from volunteers fasting (0 min) and after 15, 30, 45, 60, 75, 90, 105 and $120 \mathrm{~min}$ after ingestion of the sample.

\section{Results}

Wheat flour breads fermented with sourdough lactobacilli: preliminary screening

Breads were preliminary fermented with baker's yeast alone or with sourdough lactobacilli and baker's yeast at $30^{\circ} \mathrm{C}$ for $3 \mathrm{~h}$. The concentrations of RS and potentially available starch are shown in Table 3. Values of RS for breads made with white WF or WMF and fermented with baker's yeast were similar; they ranged from approximately 1.4 to $1.7 \%$ (starch basis). The concentration of RS in breads made with WF and WMF and fermented by sourdough lactobacilli and baker's yeast was approximately double $(3 \cdot 36-5 \cdot 04 \%)$. The highest formation of RS was found $(P<0.05 \%)$ in breads fermented with strains of $L$. plantarum and L. brevis. As a consequence, $L$. plantarum $\mathrm{P} 1$ and $L$. brevis $\mathrm{P} 2$ were selected for further studies. No significant differences $(P<0.05 \%)$ for RS were found when WF or WMF were fermented with sourdough lactobacilli. The same was found when the mixture (1:1) of WF and WMF (WF/WMF) was used (data not shown). Further experiments were carried out by using $\mathrm{WF} /$ WMF flour.

Rate of in vitro starch hydrolysis of breads made with dietary fibres, chemical acidification and sourdough

The rate of in vitro starch hydrolysis is considered to be a presumptive measure of the GI in healthy subjects ${ }^{18}$. Starch hydrolysis at 30-180 min and values of the hydrolysis index (HI) are reported in Table 4 and Fig. 1, respectively. In agreement with the concentration of RS, the rate of starch hydrolysis did not vary between breads made with WF or WMF and fermented by baker's yeasts alone. Except for oat fibre, no decreases of the starch hydrolysis were found when the

Table 3. Potentially available starch and resistant starch in white wheat flour (WF) and wholemeal flour (WMF) breads fermented with baker's yeast alone or sourdough lactobacilli and baker's yeast*

(Mean values of three independent fermentations)

\begin{tabular}{|c|c|c|}
\hline Bread & $\begin{array}{c}\text { Potentially available starch } \\
\text { [\% (starch basis)] }\end{array}$ & $\begin{array}{l}\text { Resistant starch } \\
{[\% \text { (starch basis)] }}\end{array}$ \\
\hline WF bread $†$ & $98 \cdot 60^{\mathrm{a}}$ & $1 \cdot 40^{\mathrm{C}}$ \\
\hline WF bread fermented with Lactobacillus sanfranciscensis DA110‡ & $96.63^{\mathrm{b}}$ & $3.37^{\mathrm{b}}$ \\
\hline WF bread fermented with Lactobacillus plantarum DC400‡ & $95 \cdot 25^{\mathrm{C}}$ & $4 \cdot 75^{\mathrm{a}}$ \\
\hline WF bread fermented with Lactobacillus plantarum P1‡ & $94.96^{\mathrm{C}}$ & $5 \cdot 04^{a}$ \\
\hline WF bread fermented with Lactobacillus brevis P2 $\ddagger$ & $95 \cdot 0^{\mathrm{C}}$ & $5 \cdot 0^{\mathrm{a}}$ \\
\hline WMF breadł & $98 \cdot 26^{\mathrm{a}}$ & $1.72^{\mathrm{c}}$ \\
\hline WMF bread fermented with Lactobacillus sanfranciscensis DA110 & $96 \cdot 64^{\mathrm{b}}$ & $3 \cdot 36^{\mathrm{b}}$ \\
\hline WMF bread fermented with Lactobacillus plantarum DC400‡ & $95 \cdot 52^{\mathrm{bc}}$ & $4.48^{\mathrm{ab}}$ \\
\hline WMF bread fermented with Lactobacillus plantarum $\mathrm{P} 1 \ddagger$ & $94.97^{\mathrm{C}}$ & $5 \cdot 03^{\mathrm{a}}$ \\
\hline WMF bread fermented with Lactobacillus brevis P2 $\ddagger$ & $95.03^{c}$ & $4.97^{a}$ \\
\hline
\end{tabular}

a,b,c Mean values within a column with unlike superscript letters were significantly different $(P<0.05)$.

* For details of ingredients and bread making, see Table 2 and Materials and Methods.

†Fermented with baker's yeast alone.

$\ddagger$ Fermented with sourdough lactobacilli and baker's yeast. 
Table 4. Degree of starch hydrolysis at various times*

(Mean values of three independent fermentations)

\begin{tabular}{|c|c|c|c|c|c|c|}
\hline \multirow[b]{2}{*}{ Bread } & \multicolumn{6}{|c|}{ Degree of hydrolysis (\%) } \\
\hline & $30 \mathrm{~min}$ & $60 \mathrm{~min}$ & $90 \mathrm{~min}$ & $120 \mathrm{~min}$ & $150 \mathrm{~min}$ & $180 \mathrm{~min}$ \\
\hline WF† & $12 \cdot 00^{\mathrm{a}}$ & $20 \cdot 68^{\mathrm{a}}$ & $30 \cdot 30^{\mathrm{a}}$ & $34.45^{a}$ & $43 \cdot 12^{\mathrm{a}}$ & $48 \cdot 00^{\mathrm{a}}$ \\
\hline \multicolumn{7}{|l|}{ Fibre-enriched breads } \\
\hline WMFt & $12 \cdot 20^{\mathrm{a}}$ & $20 \cdot 90^{\mathrm{a}}$ & $30 \cdot 24^{a}$ & $33.65^{a}$ & $42 \cdot 31^{\mathrm{a}}$ & $47 \cdot 88^{\mathrm{a}}$ \\
\hline WF/WMF† & $13 \cdot 11^{\mathrm{a}}$ & $21 \cdot 34^{\mathrm{a}}$ & $31.09^{a}$ & $33.54^{\mathrm{a}}$ & $41 \cdot 61^{\mathrm{a}}$ & $49.69^{\mathrm{a}}$ \\
\hline WF/WMFt and dextran & $13 \cdot 23^{\mathrm{a}}$ & $20 \cdot 07^{\mathrm{a}}$ & $29 \cdot 85^{\mathrm{a}}$ & $34 \cdot 14^{\mathrm{a}}$ & $40 \cdot 36^{\mathrm{a}}$ & $48 \cdot 72^{\mathrm{a}}$ \\
\hline WF/WMFt and sugarbeet fibre & $12.24^{\mathrm{a}}$ & $20.33^{a}$ & $31.54^{\mathrm{a}}$ & $33.41^{\mathrm{a}}$ & $40.22^{\mathrm{a}}$ & $46.50^{\mathrm{a}}$ \\
\hline WF/WMFt and oat fibre & $10 \cdot 31^{\mathrm{ab}}$ & $18 \cdot 30^{\mathrm{bc}}$ & $27 \cdot 32^{\mathrm{ba}}$ & $30.00^{\mathrm{ab}}$ & $37.47^{\mathrm{ab}}$ & $42 \cdot 12^{\mathrm{ab}}$ \\
\hline \multicolumn{7}{|l|}{ Chemically acidified breads } \\
\hline WF/WMFt and acetic acid $(\Delta \mathrm{pH} 0.5)$ & $8 \cdot 80^{\mathrm{b}}$ & $19 \cdot 16^{\mathrm{ab}}$ & $28.07^{\mathrm{ab}}$ & $30 \cdot 33^{a b}$ & $40.00^{\mathrm{a}}$ & $43.00^{\mathrm{ab}}$ \\
\hline WF/WMF† and lactic acid $\Delta \mathrm{pH} 0.5)$ & $7.54^{\mathrm{b}}$ & $18 \cdot 36^{\mathrm{bc}}$ & $22.48^{\mathrm{bc}}$ & $28.43^{\mathrm{bc}}$ & $35 \cdot 17^{b}$ & $41 \cdot 16^{\mathrm{ab}}$ \\
\hline WF/WMFt and lactic and acetic acid ( $\Delta \mathrm{pH} 0.5)$ & $8 \cdot 23^{\mathrm{b}}$ & $17 \cdot 07^{\mathrm{b}}$ & $25.00^{\mathrm{b}}$ & $30 \cdot 12^{\mathrm{ab}}$ & $35 \cdot 67^{\mathrm{b}}$ & $43.00^{\mathrm{ab}}$ \\
\hline WF/WMFt and lactic acid $(\Delta \mathrm{pH} 1.0)$ & $6.92^{b c}$ & $14.60^{\mathrm{c}}$ & $20.04^{c}$ & $25 \cdot 37^{\mathrm{b}}$ & $30.60^{\mathrm{C}}$ & $35 \cdot 72^{\mathrm{bc}}$ \\
\hline WF/WMF† and lactic acid $(\Delta \mathrm{pH} 1.5)$ & $6 \cdot 60^{\mathrm{bc}}$ & $12 \cdot 34^{\mathrm{d}}$ & $18 \cdot 4^{\mathrm{cd}}$ & $22 \cdot 8^{\mathrm{c}}$ & $27 \cdot 71^{\mathrm{cd}}$ & $29 \cdot 27^{c}$ \\
\hline \multicolumn{7}{|l|}{ Breads fermented by sourdough lactobacilli } \\
\hline WF/WMF $\ddagger(\Delta \mathrm{pH} 0.5)$ & $7 \cdot 32^{\mathrm{b}}$ & $14 \cdot 50^{\mathrm{C}}$ & $20 \cdot 25^{\mathrm{c}}$ & $24 \cdot 10^{\mathrm{cb}}$ & $29.90^{\mathrm{C}}$ & $38 \cdot 10^{\mathrm{b}}$ \\
\hline WF/WMF $\neq(\Delta \Delta \mathrm{pH} 1 \cdot 0)$ & $6.93^{\mathrm{b}}$ & $12 \cdot 00^{\mathrm{dc}}$ & $18.00^{\mathrm{dc}}$ & $23.75^{\mathrm{cb}}$ & $28 \cdot 16^{\mathrm{cd}}$ & $34.00^{\mathrm{bc}}$ \\
\hline WF/WMF‡ ( $\mathrm{p} \mathrm{pH} 1.5)$ & $6.66^{\mathrm{bc}}$ & $9.01^{\text {de }}$ & $17.91^{\mathrm{dc}}$ & $22 \cdot 38^{\mathrm{c}}$ & $25 \cdot 37^{d}$ & $26 \cdot 86^{\mathrm{cd}}$ \\
\hline WF/WMF $\ddagger$ and dextran $(\Delta \mathrm{pH} 0.5)$ & $7 \cdot 01^{\mathrm{b}}$ & $15 \cdot 22^{\mathrm{bc}}$ & $20 \cdot 08^{\mathrm{c}}$ & $26 \cdot 41^{\mathrm{b}}$ & $30 \cdot 47^{\mathrm{c}}$ & $35 \cdot 28^{\mathrm{bc}}$ \\
\hline WF/WMF $\ddagger$ and dextran $(\Delta \mathrm{pH} 1.5)$ & $6 \cdot 70^{\mathrm{bc}}$ & $8.77^{\mathrm{ed}}$ & $17 \cdot 86^{\mathrm{dc}}$ & $20 \cdot 1^{c d}$ & $24.58^{d}$ & $27.64^{\text {cd }}$ \\
\hline WF/WMF‡ and sugarbeet fibre $(\Delta \mathrm{pH} 0.5)$ & $7 \cdot 24^{\mathrm{b}}$ & $13.21^{\mathrm{cd}}$ & $21.07^{\mathrm{c}}$ & $25.00^{\mathrm{b}}$ & $30.56^{\mathrm{c}}$ & $35 \cdot 26^{\mathrm{bc}}$ \\
\hline WF/WMF‡ and sugarbeet fibre ( $\Delta \mathrm{pH} 1.5)$ & $6.57^{\mathrm{cb}}$ & $9.45^{\mathrm{de}}$ & $18.20^{\mathrm{dc}}$ & $20.04^{\text {cd }}$ & $25.00^{\mathrm{d}}$ & $28.72^{\mathrm{c}}$ \\
\hline WF/WMF $\ddagger$ and oat fibre $(\Delta \mathrm{pH} 0.5)$ & $7 \cdot 20^{\mathrm{b}}$ & $8 \cdot 59^{b c}$ & $20 \cdot 30^{c}$ & $22 \cdot 17^{\mathrm{c}}$ & $27.93^{\mathrm{cd}}$ & $29 \cdot 85^{c}$ \\
\hline WF/WMF‡ and oat fibre $(\Delta \mathrm{pH} 1.5)$ & $3.57^{\mathrm{d}}$ & $7.98^{\mathrm{e}}$ & $12.57^{\mathrm{e}}$ & $16 \cdot 42^{d}$ & $20.34^{e}$ & $23.47^{\mathrm{d}}$ \\
\hline
\end{tabular}

WF, white wheat flour bread; WF/WMF, WF and WMF in the ratio of 1:1; WMF, wholemeal flour bread; $\Delta \mathrm{pH}$, decrease of the initial pH of the dough.

${ }^{a-e}$ Mean values within a column with unlike superscript letters were significantly different $(P<0.05)$.

* For details of ingredients and bread making, see Table 2 and Materials and Methods.

†Fermented with baker's yeast alone.

‡Fermented with sourdough lactobacilli and baker's yeast.

other fibres were used. The HI of the bread made with WF/ WMF and enriched with oat fibre was $90.84 \%$.

The effect of organic acids and related decreases of $\mathrm{pH}$ $(\Delta \mathrm{pH})$ were determined (Table 4; Fig. 1). Lactic and acetic acids were used since they represent the major fermentation end-products during sourdough fermentation ${ }^{24}$. Overall, the rate of starch hydrolysis of breads containing acetic and lactic acids was significantly $(P<0.05)$ lower than non-acidified breads. Differences were found depending on the type and concentration of organic acids. In particular, the bread acidified with acetic acid to $\Delta \mathrm{pH} 0.5$ showed values of starch hydrolysis always higher than the corresponding bread acidified with lactic acid (Table 4). As expected, the values of the starch hydrolysis found with the mixture of lactic and acetic acids were intermediate. Besides, the rate of starch hydrolysis and $\mathrm{HI}$ decreased proportionally with the increase of $\Delta \mathrm{pH}$ as set by lactic acid. After $180 \mathrm{~min}$, the percentage of hydrolysed starch was 41.16, 35.72 and 29.27 for WF/ WMF breads with $\Delta \mathrm{pH} 0 \cdot 5,1 \cdot 0$ and $1 \cdot 5$, respectively. In agreement, the HI ranged between 84.07 and $66.05 \%$ (Fig. 1).

Chemical acidification was compared to the microbial acidification by selected sourdough lactobacilli. The cell density of lactobacilli after $3 \mathrm{~h}$ of fermentation was approximately $5 \times 10^{8}(\Delta \mathrm{pH} 0.5), 2 \times 10^{9}(\Delta \mathrm{pH} 1.0)$ and $5 \times 10^{9}(\Delta \mathrm{pH} 1.5)$ colony-forming units/g dough. For the same values of $\Delta \mathrm{pH}$, all breads fermented with sourdough lactobacilli showed a rate of starch hydrolysis markedly lower than the corresponding chemically acidified breads (Table 4). After $180 \mathrm{~min}$, the percentage of hydrolysed starch in WF/WMF was $38 \cdot 10(\Delta \mathrm{pH} 0 \cdot 5), 34 \cdot 0$
$(\Delta \mathrm{pH} 1.0)$ and $26.86(\Delta \mathrm{pH} 1.5)$. In agreement, the $\mathrm{HI}$ ranged between 74.54 and $59.62 \%$.

Selected sourdough lactobacilli were further used for bread making with enriched dietary fibres. The growth of sourdough lactobacilli was not affected by the addition of fibres (data not shown). Compared to sourdough fermented breads, the addition of dextran or sugarbeet fibre did not modify the degree of starch hydrolysis (Table 4). For instance, the bread made with sourdough WF/WMF and enriched with dextran had values of HI of 70.58 and $57.38 \%$ when $\Delta \mathrm{pH} 0.5$ and 1.5 were reached, respectively (Fig. 1). On the contrary, the addition of oat fibre to WF/WMF fermented with sourdough lactobacilli to $\Delta \mathrm{pH} 1.5$ gave the lowest value $(23.47 \%)$ of starch hydrolysis (Table 4). In agreement, the HI was $47.65 \%$ (Fig. 1).

\section{Glycaemic index in vivo test}

Bread made with sourdough WF/WMF enriched with oat fibre with $\Delta \mathrm{pH} 1.5$ was used for the in vivo determination of the blood glucose level and GI since it was characterized by the lowest value of HI. The bread made with WF and fermented with baker's yeast alone was used as the control since it was made under the same conditions, except for the use of WMF, sourdough lactic acid bacteria and oat fibre. Anhydrous glucose was used as reference. All volunteers consumed anhydrous glucose and breads according to the experimental protocol. The mean incremental blood glucose response curves during $120 \mathrm{~min}$ after sample ingestion are shown in Fig. 2. 


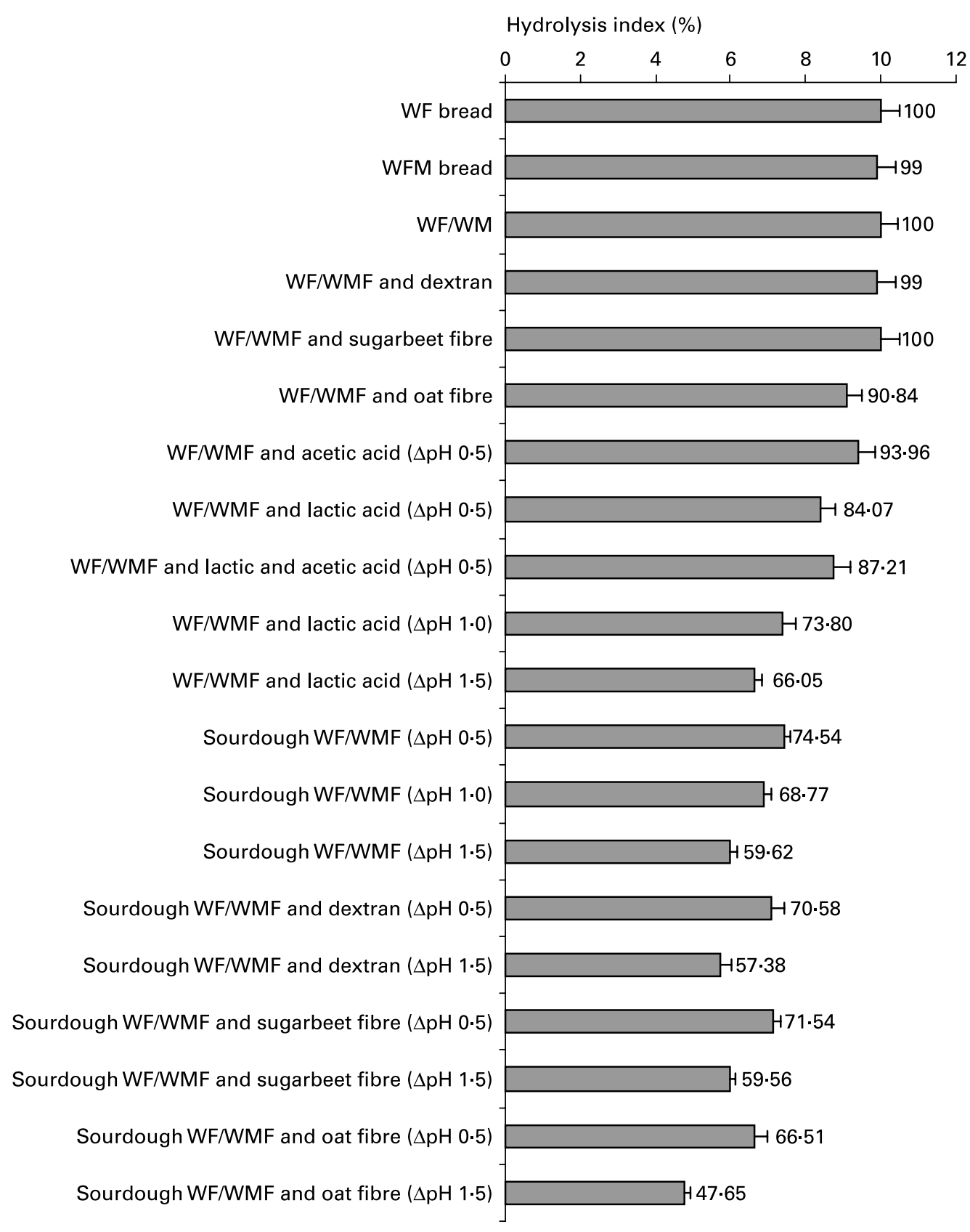

Fig. 1. Percentage of hydrolysis index of different breads calculated from $180 \mathrm{~min}$ areas. For details of bread making and ingredients, see Table 2 and Materials and Methods. Data are the mean of three independent fermentations. Sourdough WF/WMF, bread fermented with selected sourdough lactobacilli; WF, white wheat flour bread; WF/WMF, WF and WMF in the ratio of $1: 1$; WMF, wholemeal flour bread; $\Delta \mathrm{pH}$, decrease of the initial $\mathrm{pH}$ of the dough.

The GI of WF was approximately $72 \%$ of the reference (anhydrous glucose, $\mathrm{GI}=100$ ). During $120 \mathrm{~min}$ after bread ingestion, the blood glucose increment of sourdough WF/WMF bread was significantly $(P<0.05)$ lower than that of WF bread. In agreement, the GI of sourdough WF/WMF bread enriched with oat fibre was approximately $53.7 \%$.

\section{Bread characteristics}

Breads made with WF or WMF and fermented with baker's yeast alone, and sourdough WF/WMF bread were analysed for volume, bread mass, specific volume, crumb grain and sensory characteristics. WF bread had a higher volume (approximately $1340 \mathrm{ml})$ than WMF bread $(670 \mathrm{ml}$; Table 5). The volume of sourdough WF/WMF bread enriched with oat fibre was intermediate $(997 \mathrm{ml})$. On the contrary, no significant $(P<0.05 \%)$ differences were found for bread masses. Consequently, sourdough WF/WMF showed an increased specific volume $(73.91 \%)$ compared to WMF bread $(49 \cdot 16 \%)$.

The bread crumb grain was determined by image analysis technology. Digital images were pre-processed to detect crumb cell-total area by a binary conversion (black/white pixels; Fig. 3). The cell-total area of WF bread (corresponding 


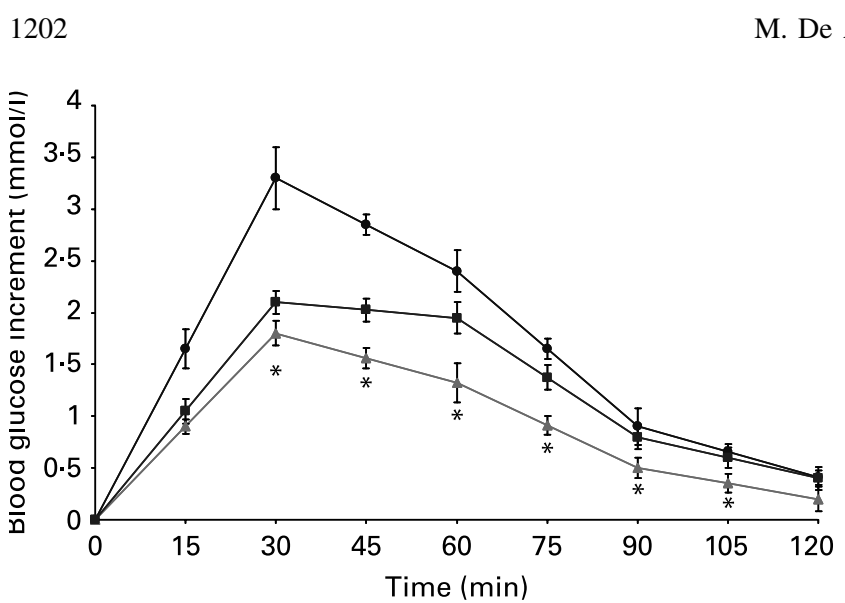

Fig. 2. Blood glucose increment $(\mathrm{mmol} / \mathrm{l})$ in healthy volunteers following ingestion of anhydrous glucose (reference; ), white wheat flour bread (WF; $\square$ ) and WF/WMF (1:1) bread enriched with oat fibre and fermented with sourdough lactobacilli to $\Delta \mathrm{pH} 1.5$ (sourdough WF/WMF; $\triangle$ ). Values are means with their standard errors depicted by vertical bars $(n 15)$. Mean sourdough WF/WMF values were significantly different from those of the WF group: ${ }^{*} P<0.05 . \Delta \mathrm{pH} 1.5$, decrease of the initial $\mathrm{pH}$ of the dough by 1.5 units.

to the black pixel total area) was $46 \%$. Crumb cell detection for WMF bread slices showed smaller and less numerous gas cells, as shown by the visual inspection of the binarized images of the breads. Indeed, a considerable variation of the cell-total area with respect to WF bread (17\% v. 46\%) was found. Substantial differences were found in the crumb features of sourdough WF/WMF bread enriched with oat fibre. The addition of WF and sourdough fermentation resulted in a larger gas cell-total area (38\%) with respect to WMF bread $(17 \%)$

Overall, sourdough WF/WMF bread enriched with oat fibre showed a higher acceptability score than WMF bread (Table 5). As expected, the presence of WMF in sourdough WF/WMF bread influenced the colour. It was darker than

Table 5. Volume, mass and sensory characteristics of white wheat flour (WF), wholemeal flour (WMF) and sourdough WF/WMF breads*

(Mean values of three independent fermentations)

\begin{tabular}{lccc}
\hline Bread characteristics & WF† & WMF† & $\begin{array}{c}\text { Sourdough } \\
\text { WF/WMF }\end{array}$ \\
\hline Volume (ml) & $1340^{\mathrm{a}}$ & $670^{\mathrm{b}}$ & $997^{\mathrm{ab}}$ \\
Bread mass (g) & $448^{\mathrm{a}}$ & $456^{\mathrm{a}}$ & $451^{\mathrm{a}}$ \\
Specific volume index (\%) & $100^{\mathrm{a}}$ & $49 \cdot 16^{\mathrm{b}}$ & $73 \cdot 91^{\mathrm{ab}}$ \\
Colour & $30^{\mathrm{b}}$ & $60^{\mathrm{a}}$ & $40^{\mathrm{ba}}$ \\
Acidulous smell & $14^{\mathrm{b}}$ & $18^{\mathrm{b}}$ & $43^{\mathrm{a}}$ \\
Acidulous taste & $30^{\mathrm{b}}$ & $32^{\mathrm{b}}$ & $60^{\mathrm{a}}$ \\
Aroma & $30^{\mathrm{b}}$ & $20^{\mathrm{c}}$ & $75^{\mathrm{a}}$ \\
Elasticity & $80^{\mathrm{a}}$ & $50^{\mathrm{b}}$ & $75^{\mathrm{ab}}$ \\
Sweetness & $50^{\mathrm{b}}$ & $53^{\mathrm{b}}$ & $60^{\mathrm{a}}$ \\
Dryness & $50^{\mathrm{a}}$ & $80^{\mathrm{b}}$ & $60^{\mathrm{ab}}$ \\
\hline
\end{tabular}

WF/WMF, WF and WMF in the ratio of 1:1.

a,b,c Mean values within a row with unlike superscript letters were significantly different $(P<0.05)$.

*Details about ingredients and bread making are described in Table 2 and Materials and Methods.

†Fermented with baker's yeast alone.

$\ddagger$ Enriched with oat fibre $(5 \%)$ and fermented with sourdough lactobacilli and baker's yeast.
WF bread. Due to the lactic acid fermentation, the sourdough WF/WMF bread enriched with oat fibre showed a more pronounced acidulous smell and taste, and a more intense aroma with respect to WF or WMF breads.

\section{Discussion}

Sourdough fermentation with selected lactobacilli improved the nutritional features of starch in white WF breads. All breads fermented with lactobacilli contained higher concentrations of RS than breads started with baker's yeasts alone. Based on its definition, RS includes starches and their partial hydrolysis products that are not digested or absorbed in the small intestinal lumen of healthy persons ${ }^{25}$. The main physiological influence of RS is concerning the: (1) inhibition of the postprandial increase of blood glucose and insulin ${ }^{26,27}$; (2) decrease of the blood lipid concentration; and (3) decrease of the concentrations of ammonia, phenol and secondary bile acid in the colon ${ }^{28}$. In agreement with previous studies $^{29-31}$, the concentration of RS $(<2.0 \%$ starch $)$ in white WF and WMF breads started with baker's yeast alone was too low to significantly interfere with the glycaemic response. An increase of the RS was found in organic acid added or sourdough fermented pumpernickel breads ${ }^{19}$. Indeed, selected sourdough L. plantarum and L. brevis strains caused the highest increase of RS in breads made with WF and WMF. Overall, the use of WMF did not influence the concentration of RS.

Consumption of foods naturally rich and/or enriched in cereal fibres is recommended to prevent several diseases ${ }^{32-34}$. Nevertheless, a large gap between dietary recommendations and daily intake of fibres is currently present in the diet of a large part of the population ${ }^{35}$. To enrich cereal baked goods with fibres by keeping optimal sensory properties is probably the most desirable goal ${ }^{11,14}$. The present study considered the use of WF in a mixture with WMF $(1: 1)$ and the addition (5\%) of different fibres (dextran, sugarbeet fibre or oat fibre) as ingredients. The mixture of WF/WMF was chosen to increase the cereal fibre content in breads. Overall, the rate of in vitro starch hydrolysis was similar in all the breads fermented with baker's yeast. As shown by the HI, only the addition of oat fibre decreased the starch availability in the bread made with WF/WMF. A large and steadily expanding body of clinical evidence attests to the extraordinary therapeutic significance of oat soluble fibre. The primary health benefits include the reduction of cholesterol ${ }^{36}$ and other risk factors for heart disease, also characterized as the metabolic syndrome (Syndrome X) ${ }^{37}$. In 1997, the Food and Drug Administration enacted a health claim addressing the cardiovascular benefits of oat $\beta$-glucan ${ }^{38}$. A $100 \mathrm{~g}$ portion of bread made with WF/WMF and enriched with oat fibre contained approximately $750 \mathrm{mg} \beta$-glucan. This amount still represents the minimum effective daily sub-dose to obtain positive effects ${ }^{38}$. As also discussed later, the results of the present study suggest an effect of oat fibre also on the decrease of the postprandial glycaemic response.

Chemical acidification decreased the rate of starch hydrolysis and HI in breads. Acetic, propionic and lactic acids have the capacity to lower the postprandial blood glucose and insulin responses in man when included in the bread formula ${ }^{39,40}$. Breads made with the mixture of WF/WMF showed the 
(A)

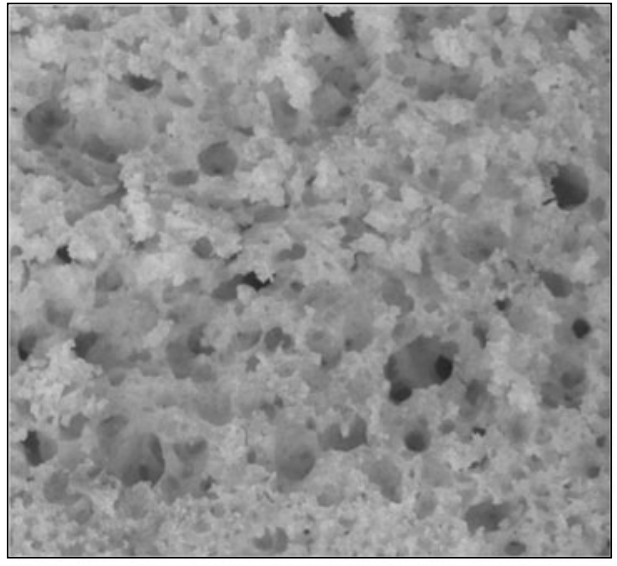

(C)

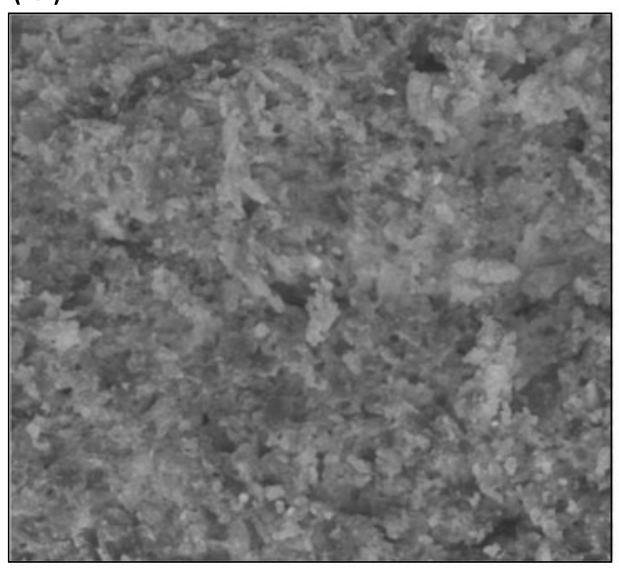

(E)

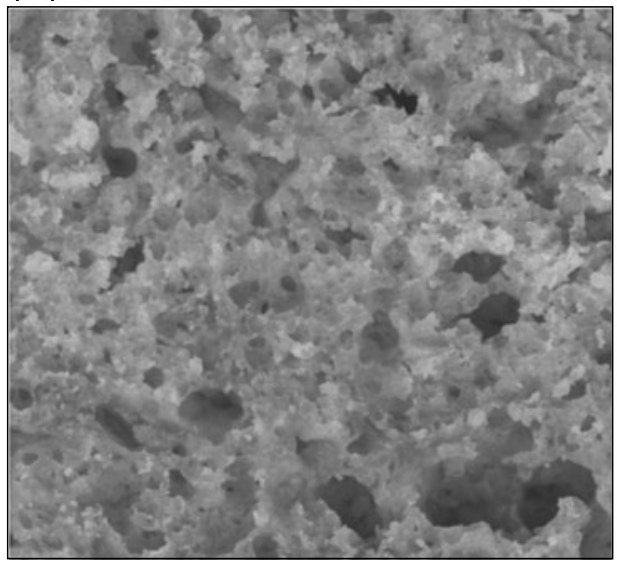

(B)

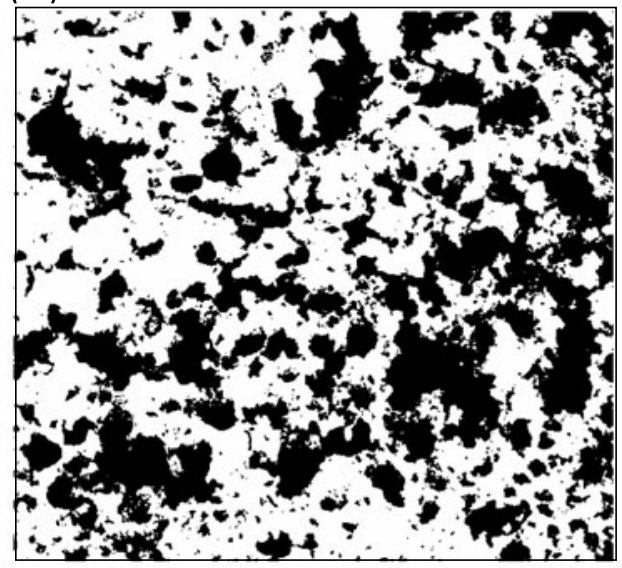

(D)

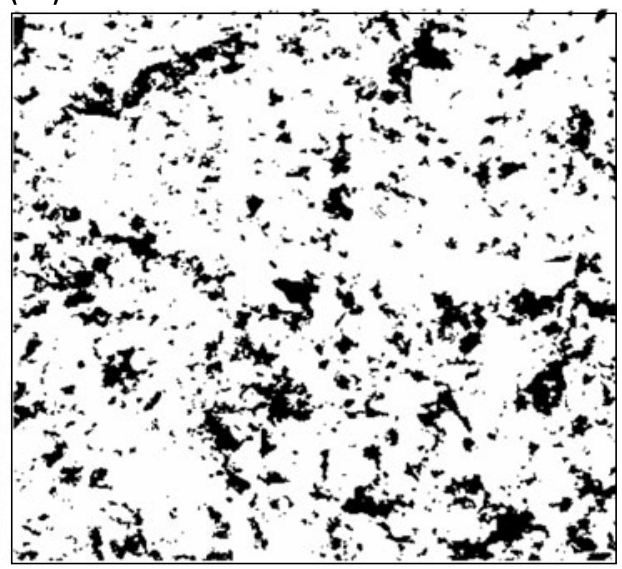

(F)

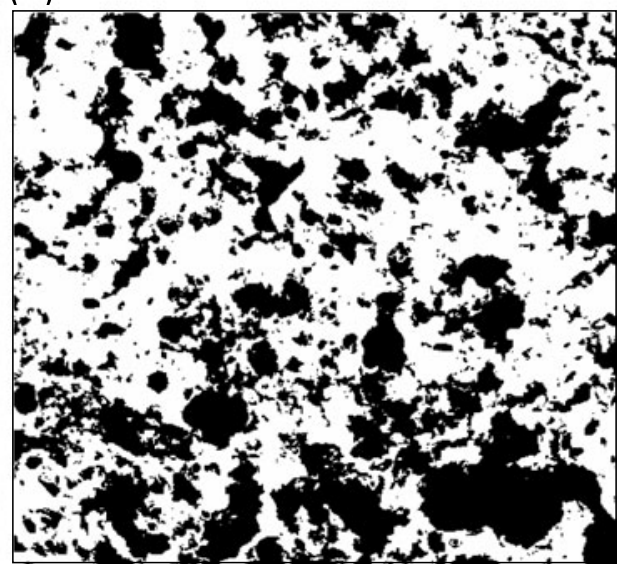

Fig. 3. Representative images of breads made with white wheat flour (WF) (A, B) or wholemeal flour (WMF) (panel C, D) and fermented with baker's yeast alone, and 1:1 WF/WMF enriched with oat fibre and fermented with sourdough lactobacilli to $\Delta \mathrm{pH} 1.5(\mathrm{E}, \mathrm{F})$. (A, C, E), Digital images of bread showing the original grey level images; $(B, D, F)$, computed binary results from grey level thresholding at the two-cluster. $\Delta \mathrm{pH} 1.5$, decrease of the initial $\mathrm{pH}$ of the dough by 1.5 units.

highest decrease of $\mathrm{HI}$ when lactic acid was used. The decrease of $\mathrm{HI}$ seemed to be concentration-dependent and the lowest values of HI were found for $\Delta \mathrm{pH} \mathrm{1.5.} \mathrm{Overall,}$ the lowering of glycemia and insulinaemia by lactic acid are not attributed to a decreased gastric emptying rate ${ }^{39}$ but to interactions between starch and gluten that limited the starch bioavailability ${ }^{40}$. For the same values of $\Delta \mathrm{pH}$, the biological acidification of WF/WMF by sourdough $L$. plantarum P1 and L. brevis $\mathrm{P} 2$ showed a higher decrease of the rate of starch hydrolysis and HI with respect to chemical acidification. This agreed with a previous study on wholemeal barley flour breads produced by sourdough, lactic acid or sodium propionate $^{41}$ (www.gilisting.com/2004/05/glycemic-index-ofbreads.html). 
When WF/WMF was enriched with dietary fibres and fermented by sourdough lactobacilli only oat fibre caused a marked decrease in the rate of starch hydrolysis and showed the lowest HI. The in vivo challenge on fifteen healthy volunteers showed that this bread caused a lower blood glucose increment compared to bread made with WF and fermented with baker's yeast alone. This bread was included in the analysis since it is consumed in large amounts in southern Europe. The value of GI calculated from glycaemic responses for sourdough WF/WMF bread enriched with oat fibre was significantly $(P<0 \cdot 05)$ lower than that of WF bread (approximately 53.7 and $72 \%$, respectively).

The sourdough WF/WMF bread enriched with oat fibre was also characterized for volume, mass, specific volume, crumb grain and sensory properties. Almost all these characteristics indicated a superior quality of sourdough WF/WMF bread enriched with oat fibre compared to bread made with WMF and fermented with baker's yeast alone. In particular, sourdough $\mathrm{WM} / \mathrm{WMF}$ showed an increased specific volume and a better cell crumb structure. In agreement with previous results ${ }^{42,43}$, the cell-total area of the bread made with WF was $46 \%$. Total cell-area of sourdough WF/WMF bread enriched with oat fibre bread was only $8 \%$ smaller than that of WF bread. Besides, sourdough WF/WMF bread enriched with oat fibre showed a more pronounced acidulous smell and taste, and an intense and more appreciated aroma with respect to WF or WMF breads. These sensory attributes are probably related to the complementary fermentative activities of $L$. plantarum P1 (facultative heterofermentative lactic acid bacterium) and L. brevis P2 (obligate heterofermentative lactic acid bacterium) ${ }^{24}$.

In most European countries, bread constitutes the major source of dietary carbohydrates. Bread with decreased GI could be included in a low-GI diet. The higher dietary fibre content frequently associated with low-GI foods may also add to the metabolic merits of a low-GI diet. Consequently, the exchange of common high-GI bread for sourdough WF/WMF bread enriched with oat fibre, as the only dietary modification, may improve the insulin economy ${ }^{11}$. The present study proposed a new biotechnology for the manufacture of a functional white WF bread enriched with oat fibre and fermented with selected sourdough lactobacilli which combined the: (1) physiologically significant supply of $\beta$-glucans; (2) decrease of the GI to $53.7 \%$ as estimated by the in vivo challenge; and (3) high standard structure and sensory characteristics.

\section{Acknowledgement}

This work was supported by the Italian Ministry of University and Research, project no. 12819, D.D. 1801 (31 December 2004).

\section{References}

1. Jenkins DJ, Kendall CW, Augustin LS \& Vuksan V (2002) High complex carbohydrate or lente carbohydrate foods? Am J Med 93, 30S-37S.

2. Salmeron J, Ascherio A, Rimm E, Colditz GA, Spiegelman D, Jenkins DJ, Stampfer MJ, Wing AL \& Willett WC (1997) Dietary fiber, glycemic load, and risk of NIDDM in men. Diabetes Care 20, 545-550.

3. Salmeron J, Manson J, Stampfer M, Colditz G, Wing A \& Willett W (1997) Dietary fiber, glycemic load, and risk of non-insulin-dependent diabetes mellitus in women. JAMA 277 , $472-477$.

4. Liu S, Willett W \& Stampfer MA (2000) Prospective study of dietary glycemic load, carbohydrate intake, and risk of coronary heart disease in US women. Am J Clin Nutr 71, 1455-1461.

5. Ludwig D (2000) Dietary glycemic index and obesity. J Nutr 130, 280S-283S.

6. Austin LS, Gallus S, Bosetti C, et al. (2003) Glycemic index and glycemic load in endometrial cancer. Int J Can 105, 404-407.

7. Jenkins DJ, Wolever TM, Ocana AM, et al. (1990) Metabolic effects of reducing rate of glucose ingestion by single bolus versus continuous sipping. Diabetes 39, 775-781.

8. Venter CS, Vorster HH \& Cummings JH (1990) Effects of the dietary propionate on carbohydrate and lipid metabolism in healthy volunteers. Am J Gastroenterol 85, 549-553.

9. Wolever TM, Brighenti F \& Royall D (1989) Effect of rectal infusion of short chain fatty acids in human subjects. $A m J$ Gastroenterol 84, 1027-1037.

10. Jenkins DJ, Kendall CW, Augustin LS, Francesci S, Hamidi M, Marchie A, Jekins AL \& Axelsen M (2002) Glycemic index: overview of implications in health and disease. Am J Clin Nutr 76, 266-273.

11. Björck IEM \& Liljeberg HGM (2003) The glycaemix index: importance of dietary fibre and other food properties. Proc Nutr Soc 62, 201-206.

12. Campbell JM, Fahey GC \& Bryan WW (1997) Selected indigestible oligosaccharides affect large bowel mass, cecal and fecal short-chain fatty acids, $\mathrm{pH}$ and microflora in rats. J Nutr $\mathbf{1 2 7}$, 130-136.

13. Jenkins DJA, Axelsen M, Kendall CWC, Augustin LSA, Vuksan V \& Smith U (2000) Dietary fibre, lente carbohydrates and the insulin-resistant diseases. Br J Nutr 83, 157-163.

14. Wang J, Rosell CM \& Benedito de Barber C (2002) Effect of the addition of different fibres on wheat dough performance and bread quality. Food Chem 79, 221-222.

15. American Association of Cereal Chemists (AACC) (1983) Approved Methods of the AACC, 8th ed. St. Paul, MN: American Association of Cereal Chemists (methods 08-01, 44-15 A, 46-13, 54-20).

16. American Association of Cereal Chemists (AACC) (1996) Approved Methods of the AACC, 9th ed. St. Paul, MN: American Association of Cereal Chemists (method 32-07).

17. Holm J, Björck IME, Drews A \& Asp NG (1986) A rapid method for the analysis of starch. Starch/Stärke 38, 224-226.

18. Åkerberg A, Liljeberg H \& Björck I (1998) Effects of amylose/ amylopectin ratio and baking conditions on resistant starch formation and glycaemic indices. J Cereal Sci 28, 71-80.

19. Liljeberg HGM, Akerberg A \& Björck IME (1996) Resistant starch formation in bread as influenced by choice of ingredients or baking conditions. Food Chem 56, 389-394.

20. El SN (1999) Determination of glycemic index for some breads. Food Chem 67, 67-69.

21. Crowley P, Grau H \& Arendt EK (2000) Influence of additives and mixing time on crumb grain characteristics of wheat bread. Cereal Chem 77, 370-375.

22. Knuckles BE, Hudson CA, Chiu MM \& Sayre RN (1997) Effect of $\beta$-glucan barley fractions in high-fiber bread and pasta. Cereal Foods Wkly 42, 94-99.

23. Haglund Å, Johansson L \& Dahlstedt L (1998) Sensory evaluation of wholemeal bread from ecologically and conventionally grown wheat. J Cereal Sci 27, 199-207.

24. Gobbetti M, De Angelis M, Corsetti A \& Di Cagno R (2005) Biochemistry and physiology of sourdough lactic acid bacteria. Trends Food Sci Technol 16, 57-69.

25. Asp NG, Tovar J \& Bairoliya S (1992) Determination of resistant starch in vitro with three different methods, and in vivo with rat model. Eur J Clin Nutr 46, 117-119. 
26. Yamada $\mathrm{Y}$, Hosoya S, Nishimura S, Tanaka T, Kajimoto $\mathrm{Y}$, Nishimura A \& Kajimoto O (2005) Effect of bread containing resistant starch on postprandial blood glucose level in humans. Biosci Biotechnol Biochem 69, 559-566.

27. Morita T, Hayashi J, Motoi H, Yagishita T, Takeya K, Sugiyama K \& Kiriyama S (2005) In vitro and in vivo digestibility of recrystallized amylase and its application for low glycemic foods. J Food Sci 70, 179-185.

28. Muir JG, Yeow EGW, Keogh J, Pizzey C, Bird AR, Sharpe K, O'Dea K \& Macrae FA (2004) Combining wheat bran with resistant starch has more beneficial effects on fecal indexes than does wheat bran alone. Am J Clin Nutr 79, 1020-1028.

29. Holm J \& Björck IME (1992) Bioavailability of starch in various wheat-based bread products: evaluation of metabolic responses in healthy subjects and rate and extent of in vitro starch digestion. Am J Clin Nutr 55, 420-429.

30. Liljerberg HGM, Lönner CH \& Björck IME (1994) Sourdough fermentation or addition of organic acids or corresponding salts to bread improves nutritional properties of starch in healthy humans. Hum Clin Nutr 22, 1503-1511.

31. Granfeldt Y, Björck Wu X \& Björck IME (2006) Determination of glycaemic index; some methodological aspects related to the analysis of carbohydrate load and characteristics of the previous evening meal. Eur J Clin Nutr 60, 104-112.

32. Murtaugh MA, Jacobs JR, Steffen LM, Jacob B \& Marquart L (2003) Epidemiological support for the protection of whole grains against diabetes. Proc Nutr Soc 62, 143-149.

33. Jacobs JDR \& Gallaher DD (2004) Whole grain intake and cardiovascular disease: a review. Curr Atheroscler Rep 6, $415-425$.
34. Larsson SC, Giovannucci E, Bergkvist L \& Wolk A (2005) Whole grain consumption and risk of colorectal cancer: a population-based cohort of 60,000 women. $B r \quad J$ Cancer 92, $1803-1897$.

35. Lang R \& Jebb S (2003) Who consumes whole grains, and how much? Proc Nutr Soc 62, 123-127.

36. Behal KM, Scholfield DJ \& Hallfrisch J (1997) Effect of betaglucan level in oat fibre extracts on blood lipids in men and women. J Am Coll Nutr 16, 46-51.

37. Ginsberg HN \& Stalenhoef AFH (2003) The metabolic syndrome: targeting dyslipidaemia to reduce coronary risk. J Cardiovasc Risk 10, 121-128.

38. FDA. The Food and Drug Adminsistration (1997) Food labelling: heath claims, oats and coronary heart disease. Final role. Fed Regist 62, 3583-3601.

39. Liljerberg HGM \& Björck IME (1998) Delayed gastric emptying rate may explain improved glycaemia in healthy subjects to a starchy meal with added vinegar. Eur J Clin Nutr 52, 368-371.

40. Östman EM, Nilsson M, Liljeberg Elmstahl HGM, Molin G \& Björck IME (2002) On the effect of lactic acid on blood glucose and insulin responses to cereal products: mechanistic studies in healthy subjects and in vitro. J Cereal Sci 36, 339-346.

41. Mendosa R (2002) Revised International Table of Glycemic Index (GI) and Glycemic Load (GL) Values. Diabetes, http:// diabetes.about.com/library/mendosagi/ngilists.htm.

42. Sapirstein HD, Roller R \& Bushuk W (1994) Instrumental measurement of bread crumb by digital image analysis. Cereal Chem 71, 383-391.

43. Gallagher E, Gormley TR \& Arendt EK (2003) Crust and crumb characteristics of gluten free breads. J Food Eng 56, 153-161. 